COMMENTARY

\title{
Cabergoline and cardiac valve disease in prolactinoma patients: additional studies during long-term treatment are required
}

\author{
M Kars, A M Pereira, J J Bax ${ }^{1}$ and J A Romijn \\ Department of Endocrinology and Metabolic Diseases, C4-R, Leiden University Medical Center, PO Box 9600, 2300 RC Leiden, The Netherlands and \\ ${ }^{1}$ Department of Cardiology, Leiden University Medical Center, PO Box 9600, 2300 RC Leiden, The Netherlands \\ (Correspondence should be addressed to J A Romijn; Email: j.a.romijn@lumc.nl)
}

\begin{abstract}
The increased risk of cardiac valve disease in patients treated for Parkinson's disease with cabergoline has raised concerns about the safety of treatment with ergot-derived dopamine agonists in patients with endocrine diseases, especially prolactinoma. Six cross-sectional studies have been published recently, of which five studies do not show an association between the treatment of prolactinoma with cabergoline during 45-79 months and clinically relevant valvular regurgitation in a total of 413 patients. Nonetheless, concern is raised because the use of cabergoline was associated in one study with an increased prevalence of moderate tricuspid regurgitation, and in two other studies with mild tricuspid regurgitation. Furthermore, the use of cabergoline was associated with increased frequencies of valvular thickening, calcifications and increased mitral tenting area. At present, the clinical relevance of these findings is still uncertain, but concern is raised with respect to the safety of the use of cabergoline in the long-term treatment of prolactinomas. Echocardiographic evaluation should be considered in patients, who require long-term treatment with cabergoline, especially in high doses. There is a need for larger, preferably prospective, studies with careful echocardiographic assessment and with longer durations of follow-up than the currently available studies.
\end{abstract}

European Journal of Endocrinology 159 363-367

\section{Introduction}

Recently, the safety of cabergoline treatment has been questioned by two population-based studies in patients with Parkinson's disease, showing an increased risk of valve regurgitation after treatment with pergolide and cabergoline $(1,2)$. Studies in patients with Parkinson's disease also observed that cabergoline is associated with an increased risk of fibrotic changes in cardiac valve leaflets. These fibrotic changes cause thickening, retraction and stiffening of the valves, which result in incomplete leaflet closure with poor coaptation, and, mostly asymptomatic, clinically relevant regurgitation.

Ergot-derived dopamine agonists, and especially cabergoline, are efficacious and well tolerated drugs in the treatment of prolactinoma by reducing both hyperprolactinaemia and pituitary adenoma volume. Cabergoline has a high affinity for 5-hydroxytryptamine (serotonin) receptor 2B (HTR2B) located on heart valves. Activation of these receptors might lead to mitogenesis and fibroblast proliferation. Histopathological investigations of cardiac valves obtained from patients after treatment with pergolide or cabergoline for Parkinson's disease resemble the histological abnormalities observed in the valves from patients with carcinoid disease and from patients taking antimigraine ergot alkaloid drugs (ergotamine, methysergide) or anorectic drugs (fenfluramine) (3-8).

In the evaluation of the severity of regurgitated cardiac valve disease, three different aspects of valvular function and morphology should be assessed. First, in the case of the presence of regurgitation, the degree of regurgitation should be assessed, e.g. rated in mild, moderate or severe regurgitation according to the recommendations of the American Society of Echocardiography (9); ideally quantitative assessment of valvular regurgitation should be performed. Second, the presence of morphological changes such as thickening and/or calcification of the valves should be evaluated, and third, the mitral tenting area and leaflet coaptation should be measured.

After the publication of the papers, which showed an increased risk of valve regurgitation after treatment with pergolide and cabergoline in patients with Parkinson's disease, six cross-sectional studies have evaluated the association between valve regurgitation and the use of cabergoline in patients treated for prolactinoma, including the study by Wakil et al. published in this edition of the European Journal of Endocrinology (Table 1) (10-15). These studies included a total of 413 patients, treated with cabergoline for 
Table 1 Cabergoline and cardiac valve disease in patients with Parkinson's disease or prolactinoma.

\begin{tabular}{|c|c|c|c|c|c|c|c|c|c|c|}
\hline Author (year) & Disease & $\begin{array}{l}\text { No. of } \\
\text { patients }\end{array}$ & $\begin{array}{l}\text { No. of } \\
\text { controls }\end{array}$ & $\begin{array}{l}\text { Gender, } \\
\text { F/M }\end{array}$ & $\begin{array}{l}\text { Age, } \\
\text { years }\end{array}$ & $\begin{array}{l}\text { Cumulative } \\
\text { dose of } \\
\text { cabergo- } \\
\text { line, mg }\end{array}$ & $\begin{array}{l}\text { Duration of } \\
\text { cabergoline } \\
\text { use, months }\end{array}$ & $\begin{array}{l}\text { Clinically, } \\
\text { relevant regurgi- } \\
\text { tation }\end{array}$ & $\begin{array}{c}\text { Valvular } \\
\text { thickening/ } \\
\text { calcification }\end{array}$ & $\begin{array}{l}\text { Mitral tenting } \\
\text { area }\end{array}$ \\
\hline Peralta (2006)(32) & M. Parkinson & 13 & 49 & $4 / 9$ & 65 & 2579 & 30 & $\begin{array}{l}\text { Sign. more } \\
\text { moderate and } \\
\text { severe } \\
\text { regurgitation }\end{array}$ & NS & NA \\
\hline Yamamoto (2006) (33) & M. Parkinson & 16 & 85 & $11 / 5$ & 65 & 4318 & 35 & $\begin{array}{l}\text { Sign. more MR, } \\
\text { AR, and TR }\end{array}$ & NS & NA \\
\hline Junghanns (2007) (34) & M. Parkinson & 24 & 38 & $8 / 16$ & 64 & 6677 & 53 & $\begin{array}{l}\text { Sign. more mild } \\
\text { and moderate } \\
\text { AR and moder- } \\
\text { ate MR }\end{array}$ & NA & NS \\
\hline Schade et al. (2007) (2) & M. Parkinson & 6 & 31 & NA & 73 & NA & NA & $\begin{array}{l}\text { Sign. more } \\
\text { regurgitation }\end{array}$ & NA & NA \\
\hline Zanettini et al. (2007) (1) & M. Parkinson & 49 & 90 & $22 / 27$ & 62 & 2820 & 24 & $\begin{array}{l}\text { Sign. more MR, } \\
\text { AR, and TR }\end{array}$ & $\begin{array}{l}\text { Sign. more } \\
\text { thickening }\end{array}$ & Sign. increased \\
\hline Kenangil (2007) ${ }^{\mathrm{a}}(35)$ & M. Parkinson & 46 & 49 & $26 / 20$ & 64 & NA & 46 & $\begin{array}{l}\text { Sign. more } \\
\text { moderate AR, } \\
\text { MR, and TR, } \\
\text { sign. } \\
\text { more mild AR }\end{array}$ & $\begin{array}{l}\text { Sign. more mitral } \\
\text { and aortic calcifi- } \\
\text { cation }\end{array}$ & NA \\
\hline Rasmussen (2008) (36) & M. Parkinson & 56 & 53 & $20 / 36$ & 63 & NA & $43^{b}$ & $\begin{array}{l}\text { Sign. more } \\
\text { moderate } \\
\text { regurgitation and } \\
\text { more AR }\end{array}$ & $\begin{array}{l}\text { Sign. more } \\
\text { thickening }\end{array}$ & NS \\
\hline $\begin{array}{l}\text { Yamashiro et al. } \\
\text { (2008) (22) }\end{array}$ & M. Parkinson & 153 & 79 & $86 / 67$ & 65 & 3000 & 36 & Sign. more AR & NA & NA \\
\hline $\begin{array}{l}\text { Lancellotti et al. } \\
\text { (2008) (10) }\end{array}$ & Prolactinoma & 102 & 51 & $73 / 29$ & 51 & $204^{b}$ & $79^{b}$ & NS & NS & Sign. increased \\
\hline $\begin{array}{l}\text { Bogazzi et al. } \\
(2008)(11)\end{array}$ & Prolactinoma & 100 & 100 & $79 / 21$ & 41 & 279 & 67 & NS & NA & NA \\
\hline $\begin{array}{l}\text { Vallette et al. } \\
\text { (2008) (13) }\end{array}$ & Prolactinoma & 70 & 70 & $37 / 33$ & 44 & 282 & 55 & NS & NS & NA \\
\hline $\begin{array}{l}\text { Kars et al. } \\
(2008)(12)\end{array}$ & Prolactinoma & 47 & 78 & $34 / 13$ & 46 & 363 & 62 & $\begin{array}{l}\text { NS (but sign. more } \\
\text { mild TR) }\end{array}$ & $\begin{array}{l}\text { Sign. more mitral } \\
\text { and aortic calcifi- } \\
\text { cation, sign. } \\
\text { more tricuspid } \\
\text { thickening }\end{array}$ & NA \\
\hline Wakil et al. (2008) (14) & Prolactinoma & 44 & 566 & $32 / 12$ & 42 & 311 & 45 & $\begin{array}{l}\text { NS (but sign. more } \\
\text { mild TR and PR) }\end{array}$ & NS & NA \\
\hline Colao et al. (2008) (15) & Prolactinoma & 50 & 50 & $44 / 6$ & 37 & 414 & NA & $\begin{array}{l}\text { Sign. more } \\
\text { moderate TR }\end{array}$ & NS & NA \\
\hline
\end{tabular}


45-79 months. Five of these studies did not find an association between clinically relevant valve regurgitation and treatment with cabergoline for prolactinoma. However, in one study moderate tricuspid regurgitation was more prevalent in patients when compared with controls (15), and two other studies showed an increased prevalence of mild tricuspid regurgitation (12, 14). Moreover, Colao et al. documented that moderate tricuspid regurgitation was significantly more prevalent in treated subjects than in de novo patients and in patients receiving a cumulative dose of cabergoline above the mean $(72 \%)$ than in those receiving a lower dose $(36 \%, P=0.036)(15)$. These observations are in agreement with potential effects of cabergoline on the valvular serotonin receptor, like in the manifestations of the classical right-sided carcinoid heart syndrome $(16,17)$. Four other studies, published in abstract form only, did not find clinically relevant valve disease, in line with the above-mentioned six publications (18-21).

The present study by Wakil et al. compared the echocardiographic data of 44 patients treated with cabergoline for prolactinoma with 566 controls from a database (14). With a mean cumulative dose of $311 \mathrm{mg}$ cabergoline, they found no increased risk in clinically relevant valve regurgitation or changes in valve morphology. However, mild tricuspid and pulmonary regurgitation were more prevalent in patients when compared with controls. Although the authors conclude, that this could be due to differences in interpretation of echocardiographic data by the observer between the two groups, whereas the ultrasounds of patients treated with cabergoline were more accurately evaluated for regurgitation than those of the control group. However, this observation is in line with two other previous studies $(12,15)$. Therefore, the observations on the association between the use of cabergoline and subclinical tricuspid regurgitation in three out of the six currently available studies raise serious concern with respect to the safety of the long-term use of cabergoline, and possibly of other ergot-derived dopamine agonists.

There are a number of methodological considerations in the interpretation of the data presented in the studies. The number of patients and controls was relatively small in these studies. Moreover, minor degrees of regurgitation were also found in some of the controls. Some studies used controls from echocardiographic data bases, which may be subject to selection bias. In general, the studies had a low power to detect small effects of cabergoline on valve characteristics. Doubleblind randomized controlled trials are considered the most rigorous to document the benefits of a certain therapeutic approach. However, rare adverse effects are likely to be missed in these trials, especially in the case of smaller studies in relatively rare diseases like prolactinoma, and especially when these adverse effects take many years to develop. Therefore, the combination of data warrant more studies with a longer follow-up and more patients to interpret with certainty the clinical relevance of the effects of cabergoline on the right side of the heart.

\section{Cabergoline and cardiac valve disease: prolactinoma versus Parkinson's disease}

Patients treated with cabergoline for prolactinoma differ in several important aspects from patients treated for Parkinson's disease. They differ in age and gender, and, importantly, in cumulative dose of cabergoline and duration of therapy. As shown in Table 1, patients treated for Parkinson's disease are usually $\sim 65$ years of age, compared with $\sim 45$ years in prolactinoma patients. In patients with Parkinson's disease there is a more or less equal sex ratio, whereas prolactinoma patients have a female preponderance. The cumulative dose used in Parkinson's disease is probably the most important explanation of discrepancy in the development of cardiac valve disease in patients treated for Parkinson's disease and not in patients treated for prolactinoma. The cumulative dose of cabergoline ranged in several studies between 2600 and $6700 \mathrm{mg}$ in patients with Parkinson's disease, whereas, in patients treated for prolactinoma, the cumulative dose is more than a factor 10 lower: $200-500 \mathrm{mg}$. This finding is also supported by a study reported by Yamashiro et al. (22). They showed that cabergoline use in Parkinson's disease was associated with statistically significant increased frequency of aortic regurgitation. Subgroup analysis of patients treated with higher daily dosages of $2.5 \mathrm{mg}$, higher cumulative dose of $3 \mathrm{~g}$ or longer treatment duration of 35 months showed increased adjusted (for age and sex) odds ratios for aortic regurgitation, which were significantly higher (14.41, 15.29 and 12.99 respectively) in cabergoline users, compared with controls.

Five of the six recently published studies in prolactinoma patients evaluated the relation between the use of cabergoline and morphological changes of the valves, and one study found significantly more frequent thickening and calcifications of cardiac valves in patients treated with cabergoline compared with controls (12). In Parkinson's disease, five studies have evaluated thickening and calcification of valves, and three of these studies found an increased frequency of these fibrotic changes. It should be noted that the echocardiographist needs to be experienced in the evaluation of these, mostly subtle, morphological changes. Moreover, currently there are no specific guidelines available for the scoring of valvular thickening, calcification and/or stiffness. Consequently, this qualitative assessment of valvular morphology most likely will have a significant interobserver variability.

The mitral tenting area is a quantitative index of modification of the valve structure, and is related to the 
severity of regurgitation. Leaflet stiffening and the subsequent apical displacement cause an increase in this area, and result in incomplete mitral leaflet closure and valve regurgitation. Several studies in patients with Parkinson's disease have shown an association between treatment with pergolide or cabergoline and an increased mitral tenting area $(1,23,24)$. In patients treated for prolactinoma, only Lancellotti et al. measured the mitral tenting area, and reported a significantly increased area in patients treated with cabergoline, and, moreover, an association of increased area with more severe mitral regurgitation (10). An increase in mitral tenting area might be an early sign of alterations of cardiac valve structure, and this measurement should be included in future echocardiographic studies in prolactinoma patients.

In contrast to cabergoline, the ergot-derived dopamine agonists lisuride and bromocriptine are potent antagonists of the HTR2B $(25,26)$, and there is only one case report on fibrotic valve changes during the use of bromocriptine (27). Evaluation of the association between the use of these drugs or non-ergot-derived dopamine agonist quinagolide and cardiac valve disease are scarce in Parkinson's disease and prolactinoma (12, 28 ). Both studies could not confirm the findings found in patients treated with pergolide or cabergoline. Furthermore, a meta-analysis of seven cross-sectional studies including 477 patients treated with ergotderived dopamine agonists pergolide or cabergoline and 127 patients treated with non-ergot-derived dopamine agonists for Parkinson's disease performed by Simonis et al. showed moderate to severe valvular disease of $26 \%$ in patients treated with ergot-derived dopamine agonists, and of $10 \%$ in non-ergot-derived dopamine agonists and $10 \%$ in controls $(n=364)$ (29).

An important question is why certain patients develop cardiac valve disease and other patients not? There seems to be an individual susceptibility of the HTR2B on cardiac valves for the agonist activity or affinity of cabergoline. It is possible that pharmacogenetic mechanisms are involved in the susceptibility of developing valvular complications during the use of dopamine agonists like cabergoline, since polymorphisms of the serotonin receptor have been described $(30,31)$.

\section{Conclusion}

There are several observations on subclinical cardiac valve disease in patients using cabergoline that raise serious concerns with respect to the safety of the long-term use of cabergoline. These include the documentation of mild and moderate tricuspid regurgitation, and subtle changes in cardiac valves such as calcifications, thickening and increased mitral tenting area, even after a cumulative dose of cabergoline of only $300 \mathrm{mg}$. We agree with the conclusion of Colao et al. that echocardiographic evaluation is indicated in patients, who require long-term treatment with cabergoline, especially in high doses (15). Furthermore, there is a need for larger, preferably prospective, studies with careful echocardiographic assessment and with longer durations of follow-up than the currently available studies.

\section{Disclosure statement}

All the authors have nothing to declare.

\section{References}

1 Zanettini R, Antonini A, Gatto G, Gentile R, Tesei S \& Pezzoli G. Valvular heart disease and the use of dopamine agonists for Parkinson's disease. New England Journal of Medicine 2007356 39-46.

2 Schade R, Andersohn F, Suissa S, Haverkamp W \& Garbe E. Dopamine agonists and the risk of cardiac-valve regurgitation. New England Journal of Medicine 2007356 29-38.

3 Pritchett AM, Morrison JF, Edwards WD, Schaff HV, Connolly HM \& Espinosa RE. Valvular heart disease in patients taking pergolide. Mayo Clinic Proceedings 200277 1280-1286.

4 Horvath J, Fross RD, Kleiner-Fisman G, Lerch R, Stalder H, Liaudat S, Raskoff WJ, Flachsbart KD, Rakowski H, Pache JC, Burkhard PR \& Lang AE. Severe multivalvular heart disease: a new complication of the ergot derivative dopamine agonists. Movement Disorders 200419 656-662.

5 Pinero A, Marcos-Alberca P \& Fortes J. Cabergoline-related severe restrictive mitral regurgitation. New England Journal of Medicine $20053531976-1977$.

6 Rothman RB, Baumann MH, Savage JE, Rauser L, McBride A, Hufeisen SJ \& Roth BL. Evidence for possible involvement of 5HT(2B) receptors in the cardiac valvulopathy associated with fenfluramine and other serotonergic medications. Circulation 2000 $1022836-2841$.

7 Simula DV, Edwards WD, Tazelaar HD, Connolly HM \& Schaff HV. Surgical pathology of carcinoid heart disease: a study of 139 valves from 75 patients spanning 20 years. Mayo Clinic Proceedings 2002 77 139-147.

8 Connolly HM, Crary JL, McGoon MD, Hensrud DD, Edwards BS, Edwards WD \& Schaff HV. Valvular heart disease associated with fenfluramine-phentermine. New England Journal of Medicine 1997 337 581-588.

9 Zoghbi WA, Enriquez-Sarano M, Foster E, Grayburn PA, Kraft CD, Levine RA, Nihoyannopoulos P, Otto CM, Quinones MA, Rakowski H, Stewart WJ, Waggoner A \& Weissman NJ. Recommendations for evaluation of the severity of native valvular regurgitation with two-dimensional and Doppler echocardiography. Journal of the American Society of Echocardiography $2003 \mathbf{1 6}$ 777-802.

10 Lancellotti P, Livadariu E, Markov M, Daly AF, Burlacu MC, Betea D, Pierard L \& Beckers A. Cabergoline and the risk of valvular lesions in endocrine disease. European Journal of Endocrinology $20081591-5$.

11 Bogazzi F, Buralli S, Manetti L, Raffaelli V, Cigni T, Lombardi M, Boresi F, Taddei S, Salvetti A \& Martino E. Treatment with low doses of cabergoline is not associated with increased prevalence of cardiac valve regurgitation in patients with hyperprolactinaemia. International Journal of Clinical Practice, 2008. PMID 18462372 (in press).

12 Kars M, Delgado V, Holman ER, Feelders RA, Smit JW, Romijn JA, Bax JJ \& Pereira AM. Aortic valve calcification and mild tricuspid regurgitation, but no clinical heart disease after 8 years of dopamine agonist therapy for prolactinoma. Journal of Clinical Endocrinology and Metabolism, 2008. PMID 18559921 (in press). 
13 Vallette S, Serri K, Rivera J, Santagata P, Delorme S, Garfield N, Kahtani N, Beauregard H, Aris-Jilwan N, Houde G \& Serri O. Longterm cabergoline therapy is not associated with valvular heart disease in patients with prolactinomas. Pituitary, 2008. PMID 18594989 (in press).

14 Wakil A, Rigby A, Clark A \& Atkin S. Low dose cabergoline for hyperprolactinaemia is not associated with clinically significant valvular heart disease. European Journal of Endocrinology, 2008. PMID 18625690 (in press).

15 Colao A, Galderisi M, Di Sarno A, Pardo M, Gaccione M, D’Andrea M, Guerra E, Pivonello R, Lerro G \& Lombardi G. Increased prevalence of tricuspid regurgitation in patients with prolactinomas chronically treated with cabergoline. Journal of Clinical Endocrinology and Metabolism, 2008. PMID 18682513 (in press).

16 Moller JE, Connolly HM, Rubin J, Seward JB, Modesto K \& Pellikka PA. Factors associated with progression of carcinoid heart disease. New England Journal of Medicine 2003348 1005-1015.

17 Fox DJ \& Khattar RS. Carcinoid heart disease: presentation, diagnosis, and management. Heart 200490 1224-1228.

18 Nachtigall L, Valassi E, McCarthy D, Passeri J, Whitely R, Utz A, Biller BMK, Miller KK \& Klibanski A. Cardiac valvular function in hyperprolactinemic patients receiving cabergoline. Abstract Annual Meeting Endocrine Society, 2008 OR27-OR22.

19 Herring N, Szmigielski C, Becher H, Karavitaki N \& Wass JAH. Valvular heart disease and the use of cabergoline for the treatment of prolactinoma. Abstract Annual Meeting Endocrine Society, 2008 OR27-OR24.

20 Delorme S, Serri K, Beauregard C, Mircescu H, Bourdeau I, Houde G, Rivera J \& Serri O. Long-term cabergoline therapy and prevalence of valvular heart disease in patients with prolactinomas: preliminary results from a prospective multicenter study. Abstract Annual Meeting Endocrine Society, 2008 P3-747.

21 Devin JK, Lakhani VT, Byrd BF \& Blevins LS. The prevalence of valvular heart disease in a cohort of patients taking cabergoline for the management of hyperprolactinemia. Abstract Annual Meeting Endocrine Society, 2008 P3-748.

22 Yamashiro K, Komine-Kobayashi M, Hatano T, Urabe T, Mochizuki H, Hattori N, Iwama Y, Daida H, Sakai M, Nakayama T \& Mizuno Y. The frequency of cardiac valvular regurgitation in Parkinson's disease. Movement Disorders 200823 935-941.

23 Van Camp G, Flamez A, Cosyns B, Weytjens C, Muyldermans L, Van Zandijcke M, De Sutter J, Santens P, Decoodt P, Moerman C \& Schoors D. Treatment of Parkinson's disease with pergolide and relation to restrictive valvular heart disease. Lancet 2004363 1179-1183.

24 Kim JY, Chung EJ, Park SW \& Lee WY. Valvular heart disease in Parkinson's disease treated with ergot derivative dopamine agonists. Movement Disorders 200621 1261-1264.

25 Kvernmo T, Hartter S \& Burger E. A review of the receptor-binding and pharmacokinetic properties of dopamine agonists. Clinical Therapeutics $2006 \mathbf{2 8} 1065-1078$.
26 Jahnichen S, Horowski R \& Pertz HH. Agonism at 5-HT2B receptors is not a class effect of the ergolines. European Journal of Pharmacology $2005 \mathbf{5 1 3} 225-228$.

27 Serratrice J, Disdier P, Habib G, Viallet F \& Weiller PJ. Fibrotic valvular heart disease subsequent to bromocriptine treatment. Cardiology in Review $200210334-336$.

28 Hofmann C, Penner U, Dorow R, Pertz HH, Jahnichen S, Horowski R, Latte KP, Palla D \& Schurad B. Lisuride, a dopamine receptor agonist with 5-HT2B receptor antagonist properties: absence of cardiac valvulopathy adverse drug reaction reports supports the concept of a crucial role for 5-HT2B receptor agonism in cardiac valvular fibrosis. Clinical Neuropharmacology 200629 80-86.

29 Simonis G, Fuhrmann JT \& Strasser RH. Meta-analysis of heart valve abnormalities in Parkinson's disease patients treated with dopamine agonists. Movement Disorders 200722 1936-1942.

30 Arranz MJ \& de Leon J. Pharmacogenetics and pharmacogenomics of schizophrenia: a review of last decade of research. Molecular Psychiatry 200712 707-747.

31 Malhotra AK, Lencz T, Correll CU \& Kane JM. Genomics and the future of pharmacotherapy in psychiatry. International Review of Psychiatry $200719523-530$.

32 Peralta C, Wolf E, Albert H, Seppi K, Muller S, Bosch S, Wenning GK, Pachinger O \& Poewe W. Valvular heart disease in Parkinson's disease vs. controls: An echocardiographic study. Movement Disorders 200621 1109-1113.

33 Yamamoto M, Uesugi T \& Nakayama T. Dopamine agonists and cardiac valvulopathy in Parkinson disease: acase-control study. Neurology 200667 1225-1229.

34 Junghanns S, Fuhrmann JT, Simonis G, Oelwein C, Koch R, Strasser RH, Reichmann H \& Storch A. Valvular heart disease in Parkinson's disease patients treated with dopamine agonists: a reader-blinded monocenter echocardiography study. Movement Disorders 200722 234-238.

35 Kenangil G, Ozekmekci S, Koldas L, Sahin T \& Erginoz E. Assessment of valvulopathy in Parkinson's disease patients on pergolide and/or cabergoline. Clinical Neurology and Neurosurgery 2007109 350-353.

36 Rasmussen VG, Poulsen SH, Dupont E, Ostergaard K, Safikhany G \& Egeblad H. Heart valve desease associated with treatment with ergot-derived dopamine agonists: a clinical and echocardiographic study of patients with Parkinson's disease. Journal of Internal Medicine 2008263 90-98.

Received 12 August 2008

Accepted 13 August 2008 